\title{
Resistência natural da madeira de Tachigali vulgaris ao fungo xilófago Postia placenta
}

\author{
Patricia Hellenn Stallbaun ${ }^{1 *}$, Edy Eime Pereira Baraúna ${ }^{2}$, Thiago Campos Monteiro², Renato da Silva Vieira ${ }^{3}$, \\ Nilza de Lima Pereira Sales ${ }^{2}$, Leandro Silva de Oliveira ${ }^{2}$ \\ ${ }^{1}$ Universidade Federal do Tocantins, Rua Badejós, Lote 7, Chácaras 69/72, Zona Rural, C P 66, CEP 77402-970, Gurupi, TO, Brasil \\ 2Universidade Federal de Minas Gerais, Av. Universitária, 1000, Universitário, CEP 39404-547, Montes Claros, MG, Brasil \\ ${ }^{3}$ Universidade Federal de São João Del Rei, Rod. MG 424 Km 47, C P 56, CEP 37701-970, Sete Lagoas, MG, Brasil
}

"Autor correspondente:

patriciahstallbaun@gmail.com

Termos para indexação:

Podridão da madeira

Preservação da madeira

Ensaio biológico

Index terms:

Wood decay

Wood preservation

Biological assay

\begin{abstract}
Resumo - O trabalho teve como objetivo analisar a resistência natural da madeira de Tachigali vulgaris L. G. Silva \& H. C. Lima ao fungo Postia placenta (Fr.) M. J. Lars. \& Lomb., causador da podridão parda. Foram coletadas nove árvores e, da tora basal, confeccionadas seis amostras de cada indivíduo, com dimensões de $25 \mathrm{~mm}$ x $25 \mathrm{~mm}$ x $9 \mathrm{~mm}$ (radial, tangencial e axial) no sentido base ao topo. As amostras foram mantidas em contato com o fungo durante 14 semanas, em sala climatizada, sendo posteriormente secas e a perda de massa avaliada. A madeira de $T$. vulgaris se mostrou altamente resistente a P. placenta, pois o maior valor de perda de massa foi de $12,13 \%$. Foi observada correlação indireta de $82,9 \%$ entre a densidade básica e a durabilidade da madeira, porém não foi constatada influência das posições no sentido base topo na durabilidade.
\end{abstract}

\section{Natural resistence of Tachigali vulgaris wood by wood-destroying fungi Postia placenta}

Recebido em 15/04/2016

Aprovado em 06/09/2016

Publicado em 30/12/2016

\begin{abstract}
The study aimed to analyze the natural resistance of Tachigali vulgaris wood to Postia placenta fungus that causes brown rot. Nine trees were collected and from basal log we prepared six samples of each tree measuring $25 \mathrm{~mm}$ x $25 \mathrm{~mm}$ x 9 $\mathrm{mm}$ (radial, tangential and axial) from base to top. The samples were kept in contact with the fungus in an acclimatized room for 14 weeks, when samples were dried and measured weight loss. T. vulgaris wood showed high resistance to P. placenta as the greatest mass loss was $12.13 \%$. An indirect correlation of $82.9 \%$ was observed between the basic density and wood durability, but it was not observed effect of base to top position on durability.
\end{abstract}

\section{Introdução}

Os produtos à base de madeira podem ser atacados por uma gama de agentes biológicos, dependendo do local e modo de emprego. Dentre eles, estão incluídos os fungos, os insetos, as bactérias e os organismos marinhos. Em razão da frequência de ação, os principais agentes biológicos de deterioração da madeira são os fungos, que se distinguem, basicamente, em emboloradores, manchadores e apodrecedores (Stangerlin et al., 2013).

Os fungos da classe dos Basidiomicetos, que ocasionam o apodrecimento dos materiais lignocelulósicos, são causadores de podridão parda e branca e usam a celulose e hemicelulose como substrato para seu crescimento (Karp, 2012). No mercado madeireiro, produtos à base de madeira, que reconhecidamente são classificados como resistentes à deterioração por fungos, apresentam ampla aceitação e difusão de emprego e, consequentemente, agregam maior valor de comercialização (Stangerlin et al., 2011).

A resistência natural da madeira é caracterizada por sua capacidade em resistir ao ataque de agentes 
deterioradores sem tratamento preservativo (Paes, 2002). Portanto, espécies madeireiras consideradas com elevada resistência natural são aquelas que resistem à ação de agentes biológicos, físicos e químicos, sem nenhum tratamento preservativo.

A durabilidade natural da madeira é uma característica de extrema importância para seu uso efetivo, uma vez que aquelas madeiras com alta resistência natural não necessitam do uso de substâncias químicas preservativas, que muitas vezes podem afetar o ambiente. Além disso, evitam-se gastos desnecessários com a reposição de peças deterioradas (Gomes et al., 2005).

A busca por essências florestais com resistência natural a organismos xilófagos tem levado a pesquisas em outros biomas, como por exemplo o Cerrado. Este bioma é rico em espécies arbóreas, que são usadas por sua população para diversos fins, inclusive madeireiro, apesar dos estudos de potencial de uso das mesmas ainda serem insuficientes.

Dentre as espécies com potencial madeireiro, Tachigali vulgaris L. G. Silva \& H. C. Lima, popularmente conhecido como cachamorra ou carvoeiro, tem se mostrado particularmente abundante na região do Cerrado, principalmente no estado do Tocantins (Lorenzi, 1998). Pertencente à família Fabaceae-Caesalpinoideae, é uma espécie pioneira, que frequentemente inicia a sucessão secundária em áreas abertas por meio da germinação intensa de suas sementes no solo. A madeira do carvoeiro possui alto poder calorífico, sendo amplamente usada para lenha, carvão e obras civis leves (Oliveira et al., 2008).

Desta forma, estudos que visem determinar a resistência natural da madeira de espécies pouco conhecidas são justificáveis, por sua importância para novos usos, utilização correta da espécie, redução de prejuízos econômicos e diminuição dos impactos sobre as espécies com risco de extinção. O objetivo deste trabalho foi avaliar a resistência natural da madeira de T. vulgaris, com potencial para uso madeireiro, contra o ataque do fungo Postia placenta causador de podridão parda.

\section{Material e métodos}

\section{Preparo dos corpos de prova}

Para o estudo da durabilidade natural da madeira de Tachigali vulgaris, foram coletadas nove árvores, provenientes do Sul do estado do Tocantins. As árvores foram selecionadas em função do diâmetro, entre $20 \mathrm{~cm}$ e $25 \mathrm{~cm}$, tomados a $1,30 \mathrm{~m}$ do solo. A tora da base de cada árvore, com cerca de $2 \mathrm{~m}$, foi coletada e transportada para o Laboratório de Produtos Florestais da Universidade Federal do Tocantins (LPF/UFT). As toras foram desdobradas e o pranchão central utilizado para os ensaios. Foram confeccionados, de acordo com a ASTM D2017 (American Society for Testing and Materials, 1994), corpos de prova com dimensões de 25 $\mathrm{mm}$ x $25 \mathrm{~mm}$ × $9 \mathrm{~mm}$ (radial, tangencial, longitudinal), retirados em seis diferentes posições longitudinais entre a base e o topo do pranchão central.

\section{Ensaios de resistência natural}

O ensaio de apodrecimento acelerado foi realizado no Laboratório de Tecnologia da Madeira na Universidade Federal do Tocantins - campus de Gurupi, seguindo-se a metodologia descrita na norma ASTM D2017 (American Society for Testing and Materials, 1994). Foi utilizado um isolado do fungo Postia placenta (Fr.) M. J. Lars. \& Lomb. causador da podridão parda, proveniente do Laboratório de Fitopatologia da mesma Universidade.

O fungo foi multiplicado em meio de cultura de malte líquido e levado à incubadora $\left(27^{\circ} \mathrm{C} \pm 2{ }^{\circ} \mathrm{C}\right.$ e $75 \% \pm$ $2 \%$ de umidade relativa), até que o micélio recobrisse totalmente a superfície do meio, o que ocorreu em três semanas. Após, o micélio do fungo foi fragmentado em liquidificador e inoculado.

O ensaio foi montado em frascos de polietileno transparente, com boca larga, tampa rosqueável, capacidade de $190 \mathrm{~mL}$, contendo $70 \mathrm{~g}$ de solo livre de matéria orgânica, com aproximado pH 6,0 e umidade ajustada para $130 \%$ da capacidade de retenção, por meio da adição de $31 \mathrm{~mL}$ de água deionizada por frasco. Em cada frasco foi colocada uma placa de alimentação de madeira de Pinus sp., com dimensões de $35 \mathrm{~mm}$ x 29 mm x $3 \mathrm{~mm}$ e inoculada com P. placenta.

Posteriormente, os frascos foram levados à incubadora $\left(27^{\circ} \mathrm{C}\right.$ e $75 \%$ de umidade relativa) por quatro semanas, até o micélio cobrir completamente a placa suporte. Após a colonização das placas, adicionou-se um corpo de prova em cada frasco. Antes desse procedimento, os mesmos foram secos em estufa a $103{ }^{\circ} \mathrm{C} \pm 2{ }^{\circ} \mathrm{C}$ até atingirem massa constante, sendo determinado o volume e a massa de cada amostra. Os valores obtidos foram utilizados para cálculo de densidade e de perda de massa da madeira. 
O ensaio utilizou nove repetições para cada posição da árvore (total de 60 corpos de prova) somente da parte intermediária da madeira (interface cerne/alburno). Para efeito de comparação, foram utilizados seis tratamentos controle, com madeira de Pinus sp. Os frascos foram mantidos por 14 semanas em sala climatizada $\left(27^{\circ} \mathrm{C} \pm\right.$ $2{ }^{\circ} \mathrm{C}$ e $75 \% \pm 2 \%$ de umidade relativa), até a constatação nos corpos de prova de Pinus utilizados como padrão de comparação, uma perda de massa superior a $60 \%$, conforme recomendado por Paes (2002). Decorrido tal período, os corpos de prova foram secos e a perda de massa avaliada, comparando os valores com os definidos pela ASTM D2017 (American Society for Testing and Materials, 1994) e apresentados na Tabela 1.

Tabela 1. Classes de resistência a fungos xilófagos (ASTM D2017)

\begin{tabular}{ccc}
\hline $\begin{array}{c}\text { Classe de resistência } \\
\text { da madeira }\end{array}$ & $\begin{array}{c}\text { Perda de massa } \\
(\%)\end{array}$ & Massa residual (\%) \\
\hline Muito resistente & $0-10$ & $90-100$ \\
Resistente & $11-24$ & $76-89$ \\
Resistência moderada & $25-44$ & $56-75$ \\
Não-resistente & $>45$ & $<55$ \\
\hline
\end{tabular}

Fonte: American Society for Testing and Materials (1994)

\section{Análise estatística}

Os dados foram organizados em delineamento inteiramente casualizado, transformados em arcsen [raiz (perda de massa/100)], conforme proposto por Stell \& Torrie (1980), com a finalidade de garantir a homogeneidade das variâncias. Foram analisados os dados de resistência da madeira ao fungo em diferentes posições dentro da árvore. Para a comparação múltipla das médias, utilizou-se o teste de Tukey a 5\% de significância.

\section{Resultados e discussão}

A classificação quanto à resistência da madeira de Tachigali vulgaris ao fungo Postia placenta, segundo a ASTM D2017 (American Society for Testing and Materials, 1994) está apresentada na Tabela 2.

A análise de variância dos dados da perda de massa (\%) para cada posição dentro da árvore mostrou que a posição 1 , mais próxima à base não apresentou perda de massa. Comportamento semelhante também ocorreu nas amostras do topo e da posição central (amostras 2 e 3) do pranchão. Estes resultados classificam a madeira de T. vulgaris como resistente ou muito resistente ao ataque do fungo.

Tabela 2. Classe de resistência da madeira de Tachigali vulgaris ao fungo Postia placenta de acordo com a posição longitudinal do pranchão central.

\begin{tabular}{ccc}
\hline Posição & $\begin{array}{c}\text { Classe de } \\
\text { resistência }\end{array}$ & Médias $^{1}$ \\
\hline 1 - Base & MR & $0,00 \mathrm{~b}$ \\
2 & $\mathrm{R}$ & $0,29 \mathrm{a}$ \\
3 & $\mathrm{R}$ & $0,24 \mathrm{ab}$ \\
4 & $\mathrm{R}$ & $0,25 \mathrm{ab}$ \\
5 & $\mathrm{R}$ & $0,28 \mathrm{a}$ \\
$6-$ Topo & $\mathrm{MR}$ & $0,14 \mathrm{ab}$ \\
\hline Controle & $\mathrm{NR}$ & 0,77 \\
\hline CV & - & 92,31 \\
\hline
\end{tabular}

${ }^{1}$ As médias da perda de massa foram transformadas em arcsen ([raiz (perda de massa/100)]. Médias seguidas pela mesma letra não diferem entre si pelo teste de Tukey (P > 0,05). Classificação de acordo com ASTM D 2017 (1994) = MR- muito resistente; R- resistente; NR- não resistente.

As amostras classificadas como muito resistentes estão nas regiões que apresentaram visualmente maior percentual de cerne. As árvores de T. vulgaris foram obtidas do cerrado, bioma com árvores naturalmente tortuosas e consequentemente com a presença do lenho de tração. A Figura 1 apresenta a distribuição do cerne na face dos pranchões centrais bem como a localização da medula ao longo da peça.

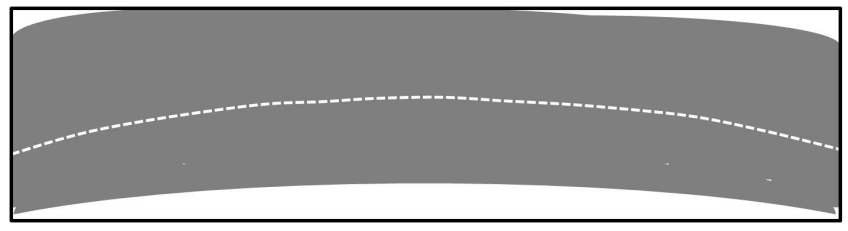

Figura 1. Esquema ilustrando a face do pranchão central de T. vulgaris com a distribuição do cerne (cor cinza) ao longo da peça e a posição da medula (linha pontilhada).

Possivelmente, este maior percentual de área cernificada nestas regiões explique a alta resistência ao fungo. A maior resistência do cerne é relatada em diversos trabalhos na literatura (Thulasidas et al., 2006; Moya \& Berrocal, 2010; Moya et al., 2014). 
Além disso, a posição da medula fora do centro geométrico da tora indica a presença do lenho de tração (Ferreira et al., 2008). A presença deste lenho altera as propriedades químicas da madeira (Abdel-Aal et al., 2011). Os mesmos autores relatam que este tipo de lenho reflete em menores teores de lignina e extrativos. Estes componentes interferem na resistência natural da madeira (Arora \& Gill, 2000; Almeida et al., 2012) e estas alterações aliadas à distribuição do cerne e alburno podem explicar a diferença entre a região "muito resistente" e "resistente".

É importante também relatar que a madeira de $T$. vulgaris apresenta maior resistência, quando comparada com o tratamento controle (Pinus). Esses resultados corroboram com as afirmativas de Costa et al. (2005), que ao analisarem a durabilidade de madeiras tratadas e não tratadas, após 10 anos em campo de apodrecimento, concluíram que entre as não tratadas os moirões de $T$. vulgaris foram os que apresentaram as melhores médias de sanidade quando comparadas com Eucalyptus saligna; E. grandis e Pinus elliottii var. elliottii, demonstrando assim ser uma espécie resistente ao ataque de fungos e cupins.

Vários comportamentos da variação longitudinal da densidade básica da madeira são descritos por Panshin $\&$ De Zeew (1980). Considerando apenas a tora da base com $2 \mathrm{~m}$ de comprimento, a espécie $T$. vulgaris não se enquadra no modelo em que a densidade é decrescente até o meio do tronco e crescente deste ponto até o topo, pois não foram observadas diferenças entre as amostras (Tabela 3). No entanto, fatores como a distribuição do cerne e presença do lenho de tração podem interferir no comportamento da densidade ao longo do pranchão (Figura 1).

Tabela 3. Valores médios da densidade básica $\left(\mathrm{g} \mathrm{cm}^{-3}\right)$ e perda de massa (\%) da madeira de Tachigali vulgaris de acordo com as posições longitudinais no tronco.

\begin{tabular}{ccc}
\hline Posição & Densidade $\left(\mathbf{g ~ c m}^{-3}\right)$ & Perda massa (\%) \\
\hline 1 - Base & $0,731 \mathrm{a}$ & $0,00 \mathrm{~b}$ \\
2 & $0,719 \mathrm{a}$ & $11,08 \mathrm{a}$ \\
3 & $0,717 \mathrm{a}$ & $10,08 \mathrm{a}$ \\
4 & $0,717 \mathrm{a}$ & $11,40 \mathrm{a}$ \\
5 & $0,714 \mathrm{a}$ & $12,13 \mathrm{a}$ \\
6 - Topo & $0,730 \mathrm{a}$ & $6,51 \mathrm{~b}$ \\
\hline Controle & 0,460 & 60,00 \\
\hline
\end{tabular}

Médias seguidas pela mesma letra não diferem entre si pelo teste de Tukey $(P>0,05)$.
Os resultados da perda de massa mostram que houve menor perda de massa nas extremidades do pranchão (base e topo). As posições internas do pranchão da base para topo de T. vulgaris não apresentaram diferenças de perda de massa (Tabela 3). Os corpos de prova de Pinus (tratamento controle) apresentaram ataque com cerca de $60 \%$ de perda de massa.

Percebeu-se visualmente que os maiores valores de perda de massa das amostras ocorreram nas regiões de alburno (Tabela 3 e Figura 1). O alburno é relatado na literatura como uma madeira mais susceptível ao ataque de xilófagos (Moya et al., 2012) e uma região que deve ser tratada para determinados tipos de uso da madeira, como mourões e postes.

A relação entre a densidade básica e a perda de massa da madeira de T. vulgaris está apresentada na Figura 2.



Figura 2. Correlação entre a densidade básica e a perda de massa da madeira de Tachigali vulgaris submetida ao ataque do fungo xilófago Postia placenta.

As amostras com maiores valores de densidade apresentaram menores perdas de massa (Figura 2). Este resultado é coerente com o apresentado por Panshin \& De Zeeuw (1980), quando relatam que a densidade e a porosidade podem ser empregadas como indício da durabilidade natural, e madeiras mais densas ou menos porosas oferecem maior resistência ao apodrecimento por fungos. O mesmo fenômeno foi constatado por Melo \& Paes (2006) ao utilizarem o fungo Postia placenta para avaliação da resistência das madeiras de angico (Anadenanthera macrocarpa), aroeira (Myracrodruon urundeuva), algaroba (Prosopis juliflora), braúna (Schinopsis brasiliensis), cássia (Senna siamea), craibeira (Tabebuia aurea), cumaru (Amburana cearensis), ipê (Tabebuia impetiginosa) e do pereiro (Aspidosperma pyrifolium). Segundo Bowyer et al. (2003), madeiras que possuem uma densidade mais alta 
tendem a apresentar teores de extrativos mais elevados e uma maior resistência a organismos xilófagos.

\section{Conclusões}

A espécie Tachigali vulgaris é resistente ao fungo Postia placenta e sua madeira foi considerada resistente quando comparada com Pinus sp. Os corpos de prova da espécie com maior densidade apresentam maior resistência ao fungo, porém em relação à durabilidade entre as diferentes posições no sentido longitudinal da árvore (base, topo), os resultados não comprovaram sua influência.

\section{Referências}

Abdel-Aal, M. A. et al. Comparative study on tension and opposite woods of some species grown under Saudia Arabia condition. Middle-East Journal of Scientific Research, v. 7, n. 4, p. 490-496, 2011.

Almeida, N. A. et al. Biodeterioração de produtos à base da madeira de cedro australiano (Toona ciliata M. Roem. var. australis). Cerne, v. 18, n. 1, p. 17-26, 2012. DOI: 10.1590/S0104-77602012000100003.

American Society for Testing and Materials. ASTM D2017: standard test method of accelerated laboratory test of natural decay resistance of wood. Philadelphia, 1994. In: ASTM INTERNATIONAL. Annual book of ASTM standards. West Conshohocken, 2005.

Arora, D. S. \& Gill, P. K. Laccase production by some white rot fungi under different nutritional conditions. Bioresource Technology, v. 73, n. 2, p. 283-285, 2000. DOI: 10.1016/S0960-8524(99)00141-8.

Bowyer, J. L. et al. Forest products and wood science: an introduction. 4th. ed. Iowa: Iowa State Press, 2003. 554 p.

Costa, A. F. et al. Durabilidade de madeiras tratadas e não tratadas em campo de apodrecimento. Floresta e Ambiente, v. 12, n. 1, p. 7-14, 2005.

Ferreira, S. et al. Excentricidade da medula em clones de Eucalyptus cultivados em diferentes topografias. Cerne, v, 14, n. 4, p. 335-340, 2008.

Gomes, J. I. et al. Durabilidade de 15 espécies de madeiras amazônicas em contato com o solo em ambiente sombreado. Belém: Embrapa Amazônia Oriental, 2005. 4 p. (Embrapa Amazônia Oriental. Comunicado técnico, 148).
Karp, S. G. Characterization of laccase isoforms produced by Pleurotus ostreatus in solid state fermentation of sugarcane bagasse. Bioresource Technology, v. 114, p. 735-739, 2012. DOI: 10.1016/j. biortech.2012.03.058.

Lorenzi, H. Árvores brasileiras: manual de identificação e cultivo de plantas arbóreas nativas do Brasil. 2. ed. Nova Odessa: Plantarum, 1998. v. 2.

Melo, R. R. \& Paes, J. B. Resistência natural de quatro madeiras do semi-árido brasileiro a fungos xilófagos em condições de laboratório. Revista Caatinga, v. 19, n. 2, p. 169-175, 2006.

Moya, R. \& Berrocal, A. Wood colour variation in sapwood and heartwood of young trees of Tectona grandis and its relationship with plantation characteristics, site, and decay resistance. Annals of Forest Science, v. 67, n. 1, p. 109-118, 2010.

Moya, R. et al. A review of heartwood properties of Tectona grandis trees from fast-growth plantations. Wood Science and Technology, v. 48, n. 2, p. 411-433, 2014. DOI: 10.1007/s00226-014-0618-3.

Moya, R. et al. Relationship between wood color parameters measured by the CIELab system and extractive and phenol content in Acacia mangium and Vochysia guatemalensis from fast-growth plantations. Molecules, v. 17, p. 3639-3652, 2012. DOI: 10.3390/ molecules17043639.

Oliveira, I. R. M. et al. Biomassa e características da madeira de Sclerolobium paniculatum cultivados em diferentes níveis de adubação. Cerne, v. 14, n. 4, p. 351-357, 2008.

Paes, J. B. Resistência natural da madeira de Corymbia maculata (Hook.) K.D. Hill \& L.A.S. Johnson a fungos e cupins xilófagos, em condições de laboratório. Revista Árvore, v. 26, n. 6, p. 761-767, 2002. DOI: 10.1590/S0100-67622002000600012.

Panshin A. J. \& De Zeeuw, C. Text book of wood technology. 4th ed. New York: McGraw Hill, 1980.

Stangerlin, D. M. et al. Durabilidade natural de painéis aglomerados confeccionados com Eucalyptus grandis e Bambusa vulgaris em ensaio de apodrecimento acelerado. Ciência Rural, v. 41, n. 8, p. 1369-1374, 2011. DOI: 10.1590/S0103-84782011000800012.

Stangerlin, D. M. et al. Resistência natural da madeira de três espécies amazônicas submetidas ao ataque de fungos apodrecedores. Ciência da Madeira, v. 4, n. 1, p. 15-32, 2013.

Steel, R. G. D. \& Torrie, J. H. Principles and procedures of statistic: a biometrical approach. 2nd .ed. New York: Mc Graw Hill, 1980. $633 \mathrm{p}$.

Thulasidas, P. K. et al. Heartwood colour variation in home garden teak (Tectona grandis) from wet and dry localities of Kerala, India. Journal of Tropical Forest Science, v. 18, n. 1, p. 51-54, 2006. 
